\title{
Is safety infliximab during pregnancy in patients with inflammatory bowel disease?
}

\author{
Federico Argüelles-Arias ${ }^{1}$, Luisa Castro-Laria ${ }^{1}$, Manuel Barreiro-de-Acosta ${ }^{2}, \mathrm{M}^{\mathrm{a}}$ Valle García-Sánchez \\ Pedro Guerrero-Jiménez ${ }^{4}, M^{a}$ Rosa Gómez-García ${ }^{5}$, Patricia Cordero-Ruiz¹, Eva Iglesias-Flores ${ }^{3}$, \\ Federico Gómez-Camacho ${ }^{3}$, Enrique J. Domínguez-Muñoz ${ }^{2}$ and Juan Manuel Herrerías-Gutiérrez ${ }^{1}$ \\ Departments of Digestive Diseases. ${ }^{1}$ Hospital Universitario Virgen Macarena. Seville, Spain. ${ }^{2}$ Hospital Universitario \\ de Santiago Compostela. A Coruña, Spain. ${ }^{3}$ Hospital Universitario Reina Sofía. Córdoba, Spain. ${ }^{4} H o s p i t a l$ \\ Universitario Nuestra Sra. de Valme. Seville, Spain. ${ }^{5}$ Hospital Universitario Virgen de las Nieves. Granada, Spain
}

\begin{abstract}
Background: in most cases, inflammatory bowel disease (IBD) debuts at reproductive age. The data available in the literature show infliximab (IFX) to be a safe drug during pregnancy but there is very little evidence about the activity of the disease following drug withdrawal during pregnancy.

Aims: determine the drug's safety in pregnant women in our setting and assess its effect on the foetus, drawing on the experience of several hospitals. Secondly, observe the effect of treatment withdrawal on disease activity during pregnancy.

Material and methods: a retrospective study was conducted of women with IBD who had received IFX treatment during pregnancy in five hospitals in Spain. Disease activity was assessed using Crohn's Disease Activity Index, while UC was assessed using the Truelove-Witts Index in each trimester of pregnancy. Gestational age, weight and diseases in the foetus were determined at birth

Results: the study included 12 women with a mean age of 29 years; 4 had ulcerative colitis and 8 Crohn's disease, with mean disease duration of 7 years. All but one, who was diagnosed during pregnancy, was receiving IFX treatment at conception. Six patients received uninterrupted treatment throughout the pregnancy, 2 requested voluntary interruption and in 3 cases treatment was interrupted in the third trimester as a precaution. They received a mean IFX dose of $400 \mathrm{mg}$ every 8 weeks. Of the 6 patients who received continuous treatment, in 50\% disease was held in remission. The 6 remaining patients suspended treatment for different reasons, presenting disease recurrence in all but one case (83.3\%). Eight deliveries were vaginal and 4 by caesarean section. Newborns presented no congenital anomalies, intrauterine growth retardation or low birth weight and there was only one premature delivery.

Conclusions: although cases included in the stduy are not significant, in our experience, IFX during pregnancy is a safe treatment for the mother and the foetus. In fact, in our study and in some cases, its withdrawal may lead to a worsening of the disease. However, further control studies are required with larger samples to obtain more representative findings.
\end{abstract}

Received: 04-08-11

Accepted: 28-10-11.

Correspondence: Federico Argüelles-Arias. Department of Digestive Disease. Hospital Universitario Virgen Macarena. C/ Dr. Fedriani, 3. 41007 Sevilla, Spain. e-mail: jarguelles@telefonica.net
Key words: Inflammatory bowel disease. Crohn's disease. Ulcerative colitis. Pregnancy. Infliximab.

Argüelles-Arias F, Castro-Laria L, Barreiro-de Acosta M, GarcíaSánchez MV, Guerrero-Jiménez P, Gómez-García MR, CorderoRuiz P, Iglesias-Flores E, Gómez-Camacho F, Domínguez-Muñoz EJ, Herrerías-Gutiérrez JM. Is safety infliximab during pregnancy in patients with inflammatory bowel disease. Rev Esp Enferm Dig 2012; 104: 59-64.

\section{INTRODUCTION}

Inflammatory bowel disease (IBD) is a pathology that characteristically affects young adults who are therefore at reproductive age. Thus, the medication used for the treatment of their disease should not compromise fertility and also, it should not have a teratogenic effect in the event of conception.

Today, the fertility of this group of patients is considered to be similar to that of the general population, although either the drugs used in the disease or certain pelvic surgery, mainly colectomy with reservoir, may affect this fertility (1). It is also understood that pregnancy does not increase the risk of a new outbreak of the disease if it is inactive at the time of conception and the stability of the disease during pregnancy is also important for this to proceed as normal (2). However, other problems may occur, particularly low birth weight, if the disease is active at the time of conception (3).

There is a large therapeutic arsenal for treating IBD and the FDA has categorised the different drugs according to their potential risk to pregnancy (4). In this sense biologics, and more specifically infliximab (IFX), have been given a B category, which means that studies in animals do not show fetal risks but there have been no control studies in humans, or adverse effects have been observed in animal 
studies but these have not been confirmed in control studies in women in the first trimester.

Although IFX is a large molecule it is known that this type of drug can cross the placenta during pregnancy. Traces have been detected in foetal serum at birth, so there may be diffusion across the placenta, probably in the third trimester $(5,6)$. These findings bolster recommendations that pregnant patients should avoid IFX treatment after 30 weeks' gestation $(7,8)$. Thus, the use of IFX should probably be limited to cases in which uncontrolled activity of IBD could expose both mother and child to risks greater than those deriving from its use (9).

In this study we reviewed the use and safety of IFX in pregnant patients in various centres, observing the effect on activity in cases in which treatment was discontinued.

\section{AIMS}

Firstly, to determine the drug's safety in pregnant women in our setting and assess its effect on the fetus, drawing on the experience of several hospitals. Secondly, to study the effect of treatment withdrawal on disease activity during pregnancy.

\section{MATERIALS AND METHODS}

This was a retrospective, multicentre and observational study. Women with IBD who received treatment with IFX during pregnancy in 5 hospitals were included. The study used a data collection sheet to analyse the patients' characteristics and assess disease activity using Crohn's Disease Activity Index (CDAI), and in ulcerative colitis (UC) using the Truelove-Witts Index before pregnancy, in each trimester of pregnancy and after birth.

Fetus gestational age, weight and diseases were determined at birth. The period of exposure to the drug prior to gestation was determined as were the dose administration intervals of IFX during pregnancy. IFX dosage used was the usual in all cases. Details of the patients' characteristics are specified in table I.

Because the number of patients included was not high, a statistical analysis could not be done. The results were expressed in percentage.

\section{RESULTS}

The study included 12 women with a mean age of 29 years; 4 had UC ( 3 left-sided colitis and 1 pancolitis) and 8 Crohn's disease (5 luminal, 2 perforating and 1 stricture/perianal forms), with mean disease duration of 7 years.

5-ASA as concomitant medication was not stopped in any case when this treatment was used. In case 5, methotrexate was stopped 2 years before conception and azathioprine was not used during pregnancy in five cases because the treatment was stopped after response with IFX. All but one, who was diagnosed during pregnancy, was receiving IFX treatment at conception. Of the remaining patients: 6 received uninterrupted treatment throughout the pregnancy, 2 requested voluntary interruption and in 3 cases treatment was interrupted in the third trimester as a precaution. They received a mean IFX dose of $400 \mathrm{mg}$ every 8 weeks. Of the 6 patients who received continuous treatment, in 50\% disease was held in remission. In patients with active disease during pregnancy, only one was in remission when she became pregnant and the outbreak was mild. The other 2 had a mild-moderate outbreak, in other words, disease activity persisted during pregnancy and they required the use of corticosteroids at some point.

The 6 remaining patients suspended treatment for different reasons, presenting disease recurrence in all but one case $(83.3 \%)$. Of the 5 patients who presented activity during pregnancy, 3 were in remission when they became pregnant (Table II, Fig. 1).

The following results were obtained in terms of characteristics of deliveries and newborns: 8 deliveries were vaginal and 4 by caesarean section. Three of the caesareans were in the same hospital (following the protocol for this type of patient) and the fourth was in the patient with UC whose disease debuted during pregnancy. No newborns presented any congenital anomalies, intrauterine growth retardation or low birth weight and there was only one premature delivery (Table III).

\section{DISCUSSION}

IFX is a useful drug for keeping IBD in remission; it belongs to drug Category B in relation to pregnancy, so it is a low-risk drug during gestation and for the foetus. Two registers compiled by the laboratory itself indicate that the possibility of teratogenicity is very low. The treatment register of IFX has more than 6.000 IBD patients, including 36 pregnant women who required biological treatment prior to pregnancy (10), and Centocor 's IFX safety database includes 96 women with direct exposure to biologics (11). The Spanish BIOBDASER register informed of 11 pregnancies in 10 women treated with different anti-TNF (12) and the British register gave information about another 23 pregnancies (13), without neonatal teratogenic anomalies being observed in any of the series. There are series of cases where no congenital anomalies have been described. In the series of Mahadevan (14), which is the most widely notified to date, ten pregnant women with Crohn's disease were treated with IFX. Eight of them received IFX as a maintenance treatment, in other words, they were already being treated with the drug and two of them had this reviewed during gestation for the first time due to the worsening of their disease. All 10 pregnancies ended in live births and no infants had congenital malformations, intrauterine growth retardation or small for gestational age parameters, although three infants were premature and one had low birth weight. The study concluded that IFX during 
Table I. Epidemiological information of patients

\begin{tabular}{|c|c|c|c|c|c|c|c|c|c|c|c|c|}
\hline & Case 1 & Case 2 & Case 3 & Case 4 & Case 5 & Case 6 & Case 7 & Case 8 & Case 9 & Case 10 & Case 11 & Case 12 \\
\hline Age & 35 & 29 & 26 & 25 & 34 & 30 & 35 & 26 & 25 & 23 & 28 & 36 \\
\hline Disease type & Crohn & Crohn & Crohn & Crohn & CU & CU & Crohn & CU & Crohn & Crohn & Crohn & $\mathrm{CU}$ \\
\hline Behaviour & Luminal & $\begin{array}{l}\text { Stricture- } \\
\text { perianal }\end{array}$ & Luminal & $\begin{array}{l}\text { Perianal/ } \\
\text { luminal }\end{array}$ & $\begin{array}{l}\text { Left-sided } \\
\text { colitis }\end{array}$ & $\begin{array}{l}\text { Left-sided } \\
\text { colitis }\end{array}$ & $\begin{array}{l}\text { Perianal / } \\
\text { perforating }\end{array}$ & Pancolitis & Luminal & $\begin{array}{l}\text { Luminal / } \\
\text { perianal }\end{array}$ & Perforating & $\begin{array}{l}\text { Left-sided } \\
\text { colitis }\end{array}$ \\
\hline Smoker & Yes & No & No & No & No & No & No & Yes & Yes & Yes & No & No \\
\hline Disease duration & 6 & 11 & 6 & 5 & 7 & 5 & 7 & 7 & 5 & 10 & 12 & 4 \\
\hline Disease onset age & 29 & 18 & 20 & 20 & 27 & 26 & 27 & 19 & 20 & 12 & 16 & 32 \\
\hline Disease location & Colonic & Ileocolic & Colonic & Colon & $\begin{array}{l}\text { Left-sided } \\
\text { colitis }\end{array}$ & $\begin{array}{l}\text { Left-sided } \\
\text { colitis }\end{array}$ & Ileocolic & Pancolitis & lleon & $\begin{array}{l}\text { Colon / } \\
\text { perianal }\end{array}$ & Ileocolic & $\begin{array}{l}\text { Left-sided } \\
\text { colitis }\end{array}$ \\
\hline Prior treatment & & & & & & & & & & & & $\begin{array}{l}\text { Diagnosed } \\
\text { during } \\
\text { Pregnancy }\end{array}$ \\
\hline 5-ASA & Yes & Yes & Yes & Yes & Yes & No & No & Yes & Yes & Yes & Yes & \\
\hline AZA & Yes & Yes & No & Yes & Yes & Yes & Yes & Yes & Yes & Yes & Yes & \\
\hline Methotrexate & No & No & No & No & Yes & No & No & No & No & No & No & \\
\hline IFX & $\begin{array}{l}\text { Yes } \\
\text { (2 years) }\end{array}$ & $\begin{array}{l}\text { Yes } \\
\text { (5 years) }\end{array}$ & $\begin{array}{l}\text { Yes } \\
\text { (5 years) }\end{array}$ & $\begin{array}{l}\text { Yes } \\
\text { (4 years) }\end{array}$ & $\begin{array}{l}\text { Yes } \\
\text { (3 years) }\end{array}$ & $\begin{array}{l}\text { Yes } \\
\text { (5 years) }\end{array}$ & $\begin{array}{l}\text { Yes } \\
\text { (18 years) }\end{array}$ & Yes & Yes & $\begin{array}{l}\text { Yes } \\
\text { (3 years) }\end{array}$ & $\begin{array}{l}\text { Yes } \\
\text { ( } 5 \text { years) }\end{array}$ & \\
\hline Caesarean & No & No & No & No & No & No & Yes & Yes & Yes & No & No & Yes \\
\hline Previous surgery & No & Yes & No & No & No & No & Yes & No & No & Yes & Yes & No \\
\hline Time passed & 4 & 6 & 1 & 1 & 3 & 5 & 5 & 4 & 4 & 6 & 7 & \\
\hline & years & years & year & year & years & years & years & years & years & years & years & \\
\hline $\begin{array}{l}\text { Number of } \\
\text { pregnancies }\end{array}$ & 1 & 0 & 2 & 1 & 3 & 1 & 0 & 0 & 0 & 0 & 0 & 0 \\
\hline
\end{tabular}

pregnancy is safe and it suggested that the benefits from achieving response and maintaining remission in mothers with Crohn's disease may outweigh the risk to the fetus from exposure to the drug. Stengel and Arnold (15) reported a case of a pregnant patient with IBD who underwent treatment with IFX during her pregnancy and while nursing her infant without any abnormalities in the child. Burt et al. (16) reported a successful pregnancy that had resulted from intercourse 3 days prior to IFX infusion. Also, in a pregnant patient with psoriasis has been used (17). The findings observed in some studies of a possible increase in the number of abortions, premature births or newborns with low birth weight would seem to be more attributable to the disease itself than to the use of these treatments. In the study by Carter et al. (18) fifty-nine percent of the children had 1 or more congenital anomalies that were part of vertebral abnormalities, anal atresia, cardiac defect, tracheoesophageal, renal, and limp abnormalities (VAC-

Table II: Data from CDAI and IFX treatment

\begin{tabular}{|c|c|c|c|c|c|c|c|c|c|c|c|c|}
\hline & Case 1 & Case 2 & Case 3 & Case 4 & Case 5 & Case 6 & Case 7 & Case 8 & Case 9 & Case 10 & Case 11 & Case 12 \\
\hline \multicolumn{13}{|l|}{ Activity / Outbreak } \\
\hline Prior & Mild & Inactive & Inactive & Inactive & Inactive & Inactive & Moderate & Inactive & Moderate & Moderate & Inactive & Inactive \\
\hline First trimester & Mild & Inactive & Moderate & Inactive & Inactive & Inactive & Moderate & Mild & Moderate & Inactive & Inactive & Severe \\
\hline Second trimester & Mild & Moderate & Mild & Inactive & Inactive & Inactive & Mild & Inactive & Moderate & Moderate & Inactive & Moderate \\
\hline Third trimester & Mild & Mild & Moderate & Inactive & Inactive & Inactive & Mild & Inactive & Moderate & Inactive & Inactive & Moderate \\
\hline Postpartum & Mild & Mild & Mild & Inactive & Inactive & Inactive & Moderate & Inactive & Mild & Inactive & Inactive & Mild \\
\hline \multicolumn{13}{|l|}{ Medication } \\
\hline \multirow[t]{2}{*}{ IFX } & $1-2$ & 1 & $1-2$ & Entire & 1 & Entire & $1-2$ & Entire & Entire & Entire & Entire & \\
\hline & trimester & trimester & trimester & pregnancy & trimester & pregnancy & trimester & pregnancy & pregnancy & pregnancy & pregnancy & Induction \\
\hline \multirow[t]{3}{*}{ IFX Dose } & $5 \mathrm{mg} / \mathrm{kg}$ & $5 \mathrm{mg} / \mathrm{kg}$ & $5 \mathrm{mg} / \mathrm{kg}$ & $5 \mathrm{mg} / \mathrm{kg}$ & $5 \mathrm{mg} / \mathrm{kg}$ & $5 \mathrm{mg} / \mathrm{kg}$ & 5 mg/kg & $5 \mathrm{mg} / \mathrm{kg}$ & $5 \mathrm{mg} / \mathrm{kg}$ & $5 \mathrm{mg} / \mathrm{kg}$ & $5 \mathrm{mg} / \mathrm{kg}$ & Induction \\
\hline & every 8 & every 8 & every 8 & every 8 & every 8 & every 8 & every 8 & every 8 & every 8 & every 8 & every 8 & \\
\hline & weeks & weeks & weeks & weeks & weeks & weeks & weeks & weeks & weeks & weeks & weeks & \\
\hline IFX after delivery & Yes & Yes & Yes & Yes & Yes & Yes & Yes & Yes & No & Yes & Yes & No \\
\hline
\end{tabular}




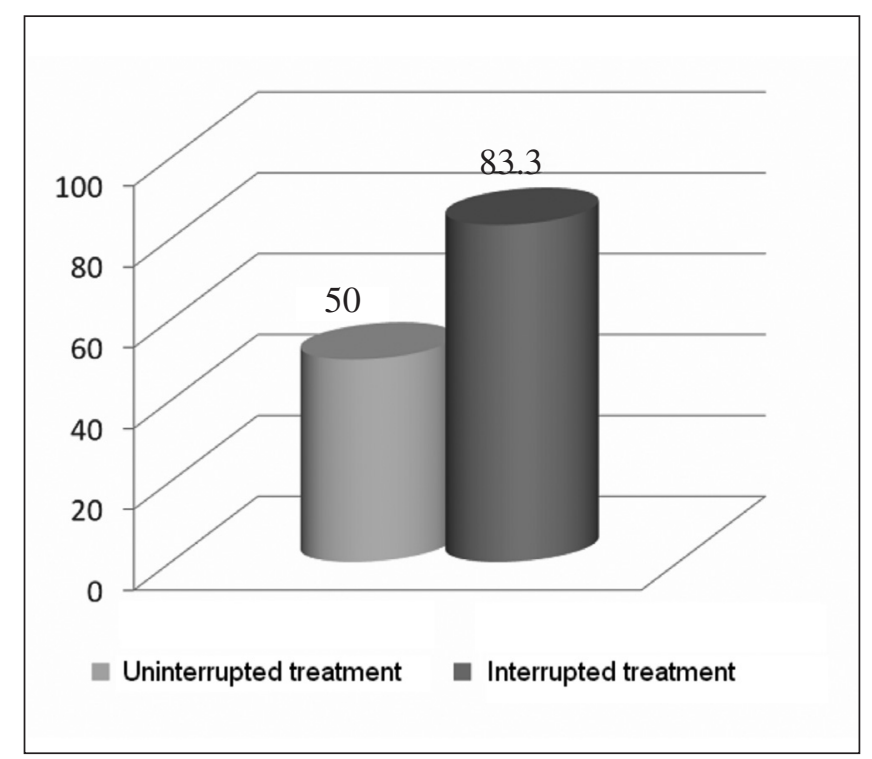

Fig. 1. Disease recurrence during pregnancy

TERL) association. Authors concluded that a seemingly high number of congenital anomalies that were part of the VACTERL spectrum had been reported. Nevertheless, Koren et al. (19), considered that these results could not be extrapolated to the general population because their results were based on a database that only collected adverse fetal outcomes. Recently a new study has just been published and concludes that direct exposure to anti-TNF treatment during pregnancy was not related to a higher incidence of adverse pregnancy outcomes than IBD overall (20). At this respect, the British Rheumatology Society consider that no firm conclusions can be drawn about the safety of anti-TNF during pregnancy so guidelines which suggest these drugs should be avoided at the time of conception cannot yet be changed (21).

However, as we know that IFX can cross the threshold the placenta in the final trimester, the interruption of treatment is recommended before week 30 , to reduce placental passage and thereby reduce levels in the newborn (22). There is also no safety data concerning the use of the drug during breastfeeding, although it appears that there is no transfer from mother to infant via breast milk. In findings from a three case study published recently, traces of IFX were not detected in children who had been breastfed (23).

The results from our study allow us to consider that IFX is a safe drug during pregnancy. Although one of the infants was premature, this was probably due to a worsening of the disease and not the medication. Also, we observed that patients whose treatment was suspended during gestation were more prone to disease recurrence. Six patients stopped treatment for different reasons, and all but one of these $(83.3 \%)$ presented disease recurrence. Of the 5 patients who presented activity during pregnancy, 3 were in remission and 2 in activity when they became pregnant. So that it seems reasonably to maintain the same treatment during pregnancy and although the literature indicates that the possibilities of the disease worsening during pregnancy are the same as not being pregnant when the activity is controlled (24), we believe that this is fundamentally conditioned by the maintenance of the medication taken by patients that allows them to be in the quiescent phase. Furthermore, of the 6 patients who continued treatment, $50 \%$ presented recurrence of their disease. But of these, only 1 was in remission when she became pregnant and the outbreak was mild. The other 2 had a mildmoderate outbreak, which meant that activity was maintained during the pregnancy and at some point they required the use of corticosteroids. This underlines the importance of choosing the moment of conception, ensuring that it occurs when the disease is controlled, as disease activity during pregnancy increases the risk of premature delivery fundamentally (25).

It is clear that our study does have its limitations. It is a retrospective, uncontrolled study with a limited number of patients, but one of its advantages is that it is a multicentre study, in which we gather experience from several hospitals and therefore different ways of acting in these clinical environments. From our results we conclude that IFX can be used during pregnancy. And perhaps, patients who become pregnant while receiving IFX should not suspend treatment, because the possible side-effects from this drug on the foetus and on the mother do not outweigh the complications that could arise from abandoning the biological treatment. These same conclusions were reached

Table III: Data of weight, gestational age and anomalies in newborns

\begin{tabular}{|c|c|c|c|c|c|c|c|c|c|c|c|c|}
\hline & Case 1 & Case 2 & Case 3 & Case 4 & Case 5 & Case 6 & Case 7 & Case 8 & Case 9 & Case 10 & Case 11 & Case 12 \\
\hline Premature delivery & No & No & Yes & No & No & No & No & No & No & No & No & No \\
\hline Weight & $\begin{array}{l}\text { Normal } \\
\text { weight }\end{array}$ & $\begin{array}{l}\text { Normal } \\
\text { weight }\end{array}$ & $\begin{array}{l}\text { Normal } \\
\text { weight }\end{array}$ & $\begin{array}{l}\text { Normal } \\
\text { weight }\end{array}$ & $\begin{array}{l}\text { Normal } \\
\text { weight }\end{array}$ & $\begin{array}{l}\text { Normal } \\
\text { weight }\end{array}$ & $\begin{array}{l}\text { Normal } \\
\text { weight }\end{array}$ & $\begin{array}{l}\text { Normal } \\
\text { weight }\end{array}$ & $\begin{array}{l}\text { Normal } \\
\text { weight }\end{array}$ & $\begin{array}{l}\text { Normal } \\
\text { weight }\end{array}$ & $\begin{array}{l}\text { Normal } \\
\text { weight }\end{array}$ & $\begin{array}{l}\text { Normal } \\
\text { weight }\end{array}$ \\
\hline Gestational age & 40 weeks & 40 weeks & 37 weeks & 39 weeks & 42 weeks & 42 weeks & 42 weeks & 38 weeks & 40 weeks & 40 weeks & 40 weeks & 38 weeks \\
\hline Retarded growth & No & No & No & No & No & No & No & No & No & No & No & No \\
\hline Congenital anomalies & No & No & No & No & No & No & No & No & No & No & No & No \\
\hline NB diseases & No & No & No & No & No & No & No & No & No & No & No & No \\
\hline
\end{tabular}


by other studies which showed that while IBD is an independent risk factor for having under-weight and premature newborns, the maintenance of medication is essential to avoid disease recurrence (26). However, further control studies are required with larger samples to obtain more representative findings.

\section{REFERENCES}

1. Garrido E, Van Domselaar M, Morales S, López-Sanromán A. Inflammatory bowel disease and pregnancy. Gastroenterol Hepatol 2010;33:517-29.

2. Raatikainen K, Mustonen J, Pajala MO, Heikkinen M, Heinonen S. The effects of pre- and post-pregnancy inflammatory bowel disease diagnosis on birth outcomes. Aliment Pharmacol Ther 2011;33: 333-9.

3. Molnár T, Farkas K, Nagy F, Lakatos PL, Miheller P, Nyári T, et al. Pregnancy outcome in patients with inflammatory bowel disease according to the activity of the disease and the medical treatment: a casecontrol study. Scand J Gastroenterol 2010;45:1302-6.

4. Food and Drug Administration. Regulations 1980;44:37434-7.

5. Vasiliauskas ED, Barry M, Dubinsky M. High serum levels of infliximab detected in the newborn of a mother receiving during pregnancy. Gastroenterology 2005;128:33.

6. Vasiliauskas EA, Church JA, Silverman N, Barry M, Targan SR, Dubinsky MC. Case report: evidence for transplacental transfer of maternally administered infliximab to the newborn. Clin Gastroenterol Hepatol 2006;4:1255-8

7. Zelinkova Z, de Haar C, de Ridder L, Pierik MJ, Kuipers EJ, Peppelenbosch MP, et al. High intra-uterine exposure to infliximab following maternal anti-TNF treatment during pregnancy. Aliment Pharmacol Ther 2011;33:1053-8

8. Friedman S, Regueiro MD. Pregnancy and nursing in inflammatory bowel disease. Gastroenterol Clin North Am 2002;31:265-73, xii.

9. Gisbert JP. Safety of immunomodulators and biologics for the treatment of inflammatory bowel disease during pregnancy and breast-feeding. Inflamm Bowel Dis 2010;16:881-95.

10. Lichtenstein G, Cohen R, Feagan B, Sandborn W, Salzberg B, Chen D. Safety of infliximab in Crohn's disease: Data from the 5000-patient TREAT registry. Gastroenterology 2004;126:A54.

11. Katz JA, Antoni C, Keenan GF, Smith DE, Jacobs SJ, Lichtenstein GR. Outcome of pregnancy in women receiving infliximab for the treatment of Crohn's disease and rheumatoid arthritis. Am J Gastroenterol 2004:99:2385-92.
12. Joven BE, García-González AJ, Ruiz T, Moreno E, Cebrián L, Valero M. Pregnancy in women receiving anti-TNF therapy. Experience in Spain. Arthritis Rheum 2005;9(Supl.):S349.

13. Hyrich KL, Symmons DP,Watson KD, Silman AJ. Pregnancy outcome in women who were exposed to anti-tumor necrosis factor agents: results from a national population register. Arthritis Rheum 2006:54: 2701-2.

14. Mahadevan U, Kane S, Sandborn WJ, Cohen RD, Hanson K, Terdiman JP, et al. DG. Intentional infliximab use during pregnancy for induction or maintenance of remission in Crohn's disease. Aliment Pharmacol Ther 2005;21:733-8.

15. Stengel JZ, Arnold HL. Is infliximab safe to use while breastfeeding? World J Gastroenterol 2008;14:3085-7.

16. Burt MJ, Frizelle FA, Barbezat GO. Pregnancy and exposure to infliximab (anti-tumor necrosis factor-alpha monoclonal antibody). J Gastroenterol Hepatol 2003;18:465-6.

17. Puig L, Barco D, Alomar A. Treatment of psoriasis with anti-TNF drugs during pregnancy: case report and review of the literature. Dermatology 2010;220:71-6.

18. Carter JD, Ladhani A, Ricca LR, Valeriano J, Vasey FB. A safety assessment of tumor necrosis factor antagonists during pregnancy: a review of the Food and Drug Administration database. J Rheumatol 2009;36:635-41.

19. Koren G, Inoue M. Do tumor necrosis factor inhibitors cause malformations in humans? J Rheumatol 2009;36:465-6.

20. Schnitzler F, Fidder H, Ferrante M, Ballet V, Noman M, Van Assche $\mathrm{G}$, et al. Outcome of pregnancy in women with inflammatory bowel disease treated with antitumor necrosis factor therapy. Inflamm Bowel Dis 2011;17:1846-54.

21. Verstappen SM, King Y, Watson KD, Symmons DP, Hyrich KL; BSRBR Control Centre Consortium, BSR Biologics Register. AntiTNF therapies and pregnancy: outcome of 130 pregnancies in the British Society for Rheumatology Biologics Register. Ann Rheum Dis 2011;70:823-6.

22. Dubinsky M, Abraham B, Mahadevan U. Management of the pregnant IBD patient. Inflamm Bowel Dis 2008:14:1736-50.

23. Kane S, Ford J, Cohen R, Wagner C. Absence of infliximab in infants and breast milk from nursing mothers receiving therapy for Crohn's disease before and after delivery. J Clin Gastroenterol 2009;43:613-6.

24. Mahadevan U, Kane S. American Gastroenterological Association Institute technical review on the use of gastrointestinal medications in pregnancy. Gastroenterology 2006;131:283-311.

25. Nørgård B, Hundborg HH, Jacobsen BA, Nielsen GL, Fonager K. Disease activity in pregnant women with Crohn's disease and birth outcomes: a regional Danish cohort study. Am J Gastroenterol 2007;102:1947-54

26. Molnár T, Farkas K, Nagy F, Lakatos PL, Miheller P, Nyári T, et al Pregnancy outcome in patients with inflammatory bowel disease according to the activity of the disease and the medical treatment: a casecontrol study. Scand J Gastroenterol 2010;45:1302-6. 